\title{
The Relationship between the Interest in Poetry and the Degree of Sensivity: A Primary Study of Sample of Khorasan-Iran Students
}

\author{
Reza Naqavi Moqaddam* \\ Muhammadiyah University of Surabaya, Jl. Sutorejo No. 59, Surabaya, East Java, Indonesia
}

\section{A B S T R A C T}

This study attempts to find a relation between the amount of interest in poetry and the degree of sensitivity, especially among the college students. If a positive correlation can be found, scholars and teachers may be able to offer students with weak perception of the environment, poetry reading. Dr. Elaine N. Aron's questionnaire, Highly Sensitive Person Scale 2007, was the tool of this paper to evaluate the hypersensitivity of students, the results of which were tested correlation with a number of five questions that was added to the original questionnaire. The added questions were to demonstrate the students' interest or disinterest toward poetry, and through Pearson Product-Moment Correlation Coefficient and independent Samples T-Test it became possible to calculate the correlation of sensitivity tests and the interest in poetry. The results answered research questions, and it was found that except the question number five, there was no significant relationship between sensitivity and the other variables. However, the question number five which showed a positive relationship between sensitivity and the amount of empathetic understanding of those who are interested in poetry, could indicate a meaningful correlation by reminding that empathy is an equivalence of unconscious admittance.
A R T I C L E I N F O

Paper type:

Research Article

Article history:

Received: 8 March 2019

Revised: 18 April 2019

Accepted: 20 April 2019

Keywords:

- Sensivity

- Poetry

- Khorasan-Iran Students

- Poetry Therapy

- HSPSCALE_2007

\section{Introduction}

There are different types of people all around the world, having different tastes and favors. Some people tend to like reading poetry or even compose a piece once in a while, while some others don't feel any enthusiasm toward poetry or even hate it altogether. These differences in people's attitudes are generally rooted in their background, 'environment' and 'heredity', i.e. related to where they have lived, and are mostly geneticallydetermined. This research attempts to find the relationship between the amount of a specific concept, Sensitivity, and the amount of interest in poetry. There is a minority of individuals who are born with a special aptitude in behavior, i.e. hypersensitivity. These people, who comprise "a minority of individuals, about 15 percent" (Aron, 1999), are characterized by their extreme sensitivity to subtle stimuli, their resistance to change, and their getting easily over-aroused. Such people are considered more emotionally inclined than others, since they have a clearer and more delicate awareness of events happening around them. This tendency causes them certain problems, such as, humiliation in the interpersonal relationships, depression, shyness, etc. (Aron, 1999)

The hypothesis is that these hypersensitive people may find solace in poetry; so as a consequence, they yearn for it. Obviously, people have different motives for reading poetry, such as seeking pleasure, gaining more refined perception and understanding, as a consolation for their problems caused by genetic and environmental factors, and as a result of their personal traits. Some personal traits of poetry lovers were discussed in the previous literature. Here, this research wants to see if there is a relationship between the amount of interest in

\footnotetext{
*E-mail addresses: r.naqavi.m@gmail.com. 
reading poetry and the degree of Sensitivity. (Furman at al., 2006; Hill \& Newall, 2004; Stepakoff, 2009). The gap of literature here is an investigation of the possibility that the Sensitivity which is a somehow newly presented concept can be an influential factor in how people feel about poetry. This paper also seeks to explain why some of these people favor poetry. Maybe they are trying to have a little containment and solace out of their 'overwhelming' environment, or looking for to heal themselves of their consequent anxieties and depressions.

\subsection{Research Questions}

(1) What is the relationship between the degree of sensitivity and the amount of time spent on reading poetry? (2) Are those interested in poetry more sensitive than those without any such interest? In other words, is there a difference between the sensitivity of those interested in poetry and those without any such interest? (3) Are those with a higher degree of creativity more sensitive than those without much creativity? In other words, is there a difference between the sensitivity of those with more creativity and those with less creativity? (4) Is there any difference between the sensitivity of those who get excited while reading poetry and those who do not show such excitement? (5) Are those persons who understand and show some empathy for the people who are interested in poetry, more sensitive than people without any such empathy?

The hypothesis is that people with a high degree of sensitivity tend to like poetry more than others, and vice versa those who like poetry and read it for out of no obligation tend to be more sensitive guys. If this hypothesis is supported, then it will be suggestible to offer sensitive people to read more and more poetry.

There is a minority of individuals, about 15 percent (Kagan, 1994), who are born with a temperamental difference that, according to diverse research, makes them more reflective, sensitive to subtle stimuli, uncomfortable with novelty (with greater sensitivity to subtle stimuli, more would be seen as novel, and novelty would be more stimulating), and easily overstimulated. As a result, those with this difference would appear cautious, inhibited, or shy. (Aron, 1999)

The limitation of the final results would be that it is not possible to be one-hundred percent sure of the answers. The number of our sample is small, and thus the sample cannot be generalized to a whole human community. If a meaningful correlation is founded, even so it can be attributed to chance and arbitrariness; and this will make any final conclusion a little unreliable. On the brighter side, these skepticisms have no subversive altering effect to be capable of changing the overall conclusions.

One last limitation of this essay is that some scholars have noted that men may often be resistant toward poetry due to their own conceptions of masculinities. In discussions about the runaway youth, Gardner has noticed that: "A number of the boys resisted the idea of poetry altogether, finding it too threatening for their masculinity or protected themselves from exposure by refusing to cooperate" (as cited in Furman \& Dill, 2012). Question number 5 tries to solve this problem; because protective men can more easily express their unconscious interest in poetry through the less repulsive admittance of empathy for other poetry lovers.

\subsection{Review of Literature}

Most individuals are not sensitive to subtle stimuli and are not easily overstimulated; on the other hand, they often seek extra stimulation and "therefore appear bold, nonfearful, or even impulsive in their behavior" (Aron, 1999). However, Aron suggest that a minority of 15 percent of people "are born with a temperamental difference that, according to diverse research, makes them more reflective, sensitive to subtle stimuli, uncomfortable with novelty [...] and easily overstimulated" (Aron, 1999). The result of such a temperament would be that they appear in their relationships more than necessary "cautious, inhibited, or shy" (Aron, 1999).

"It seems quite reasonable that sensitive persons should be more emotional, as they are aware of more and also more easily overaroused" (Aron, 1999). Social gatherings are high stimulators for human beings, so it is not strange that the sensitive persons mostly avoid these gathering. Avoidance of active social presence is a great strategy to reduce any unnecessary encounter with stimulations as they are simply overstimulated and overwhelmed by its pressures. Previous "findings implicate a relationship between AS cognitive concerns (i.e., a fear of cognitive dyscontrol) and elevated suicidal ideation" (Capron et al., 2013). People with high sensitivity are more likely to become depressed and commit suicide. It has been found that humiliation is highly associated 
with interpersonal sensitivity, and also that humiliation could be a risk factor of depression (Collazzoni et al., 2014).

Scientists found out that through art, people would be invited to contemplate about their lives. In the process of contemplation, attentiveness of people about what is happening within and around them in social environment intensifies. We must mention that " $[t]$ hrough drawings, children and adolescents with emotional and behavioral problems were able to, among others, express and externalize their thoughts and feelings, project themselves onto their artwork, and validate their perceptions" (Brillantes-Evangelista, 2013). There have been studies by NAPT website about poetry therapy, "a recognized modality employing poetry and other forms of evocative literature to achieve therapeutic goals and personal growth" (as cited in Mohammadian et al., 2011). Previous literature suggests that patients in poetry therapy sessions with the help of visual arts and poetry could construct healthy identities for themselves. Actually "[d]iscovering personal symbols can help [...] people understand and value their insights and intuitions" (Lovecky, 1986).

The "use of poetry as a method of dealing with emotional problems" traces back to "preliterate times in history" (Mohammadian et al., 2011). Mazza argues that one of the purposes of the chanted words "was to bring about change in self" (as cited in Mohammadian et al., 2011). There are several studies that report the positive effects of therapeutic poetry on a vast range of mental disorders. In this method, the poems should match the mood which the therapist wants to change. It might lead us to the hypothesis that poetry is considered as a moderator in mentally disordered people, although they might not know the reason why they are yearning for poetry and art. (Mazza \& Hayton, 2013; Mohammadian et al., 2011). It is interesting to note that "[m]any survivors of suicide have reported that [after their failed suicide], they felt compelled to search for [...] preexisting poems and songs that expressed what they were not able to find the words to express" (Stepakoff, 2009). Readers of poetry seek medium "levels of verbal complexity, each person according to his own level of individual complexity" (Kammann, 1966). Somehow related, "[r]eading poems can be used to help men who have a hard time identifying their feelings" (Furman \& Dill, 2012). One notable suggestion was that poetry may help "to develop sensitivity and moral understanding" (Hill \& Newall, 2004). One poem can be perceived in different points of view for different readers. Children "prefer poetry based on jokes and humour", whereas young readers "prefer texts that contain some mystery and hidden meanings" (Vala, 2012). It can be deduced from a research that liberal individual are more likely to seek complex and familiar music and poetry, while conservative people would prefer simple and familiar kinds (Glasgow et al., 1985). It is suggested that "some poems are understood more emotionally than rationally" (Vala \& Marešová, 2014). It is "the emotions that poetry influences most" (Vala \& Marešová, 2014).

"The complex poem [...] repays exhaustive study; the introvert can absorb it into himself and study it at leisure" (Eysenck, 1940), since such persons contemplate more, and spend more time on considering every aspect of a situation, here poetry: "The introvert takes his time; he consults his feelings and is slow to give a judgment. When he makes up his mind, he may judge less spontaneously, but perhaps more profoundly" (Eysenck, 1940). The proposition is that since poetry is, by nature, more complex than ordinary dialogues of everyday language, readers of poetry are mostly introverts. A major question here is why people read poetry at all? Apart from the characteristic, genetic, and environmental reasons, one reason can be stated thusly: generally, people read poetry for the mere pleasure of it, and to escape the world's chaos. Sonnet "form provides containment and the rhythm provides solace" (Stepakoff, 2009). As one writer has put it, scholars such as Ibrahim and Varon "have suggested that iambic pentameter has a natural comforting effect because it is similar to the rhythm of the human heartbeat, which infants hear when in proximity to their mothers" (as cited in Stepakoff, 2009). Meter gives the reader of poetry more pleasure and an aesthetic experience (Peer, 1990).

In the previous literature, there is one study that has found that people who like poetry are weak in factors such as "self-efficacy, orderliness, dutifulness, achievement-striving and cautiousness" ( et al., 2013). But these poem lovers tend to have high levels in factors such "strong degrees of imagination, artistic interest, emotionality, adventurousness, intellect and liberalism" (Cantador et al., 2013). Their personality traits also include "strong degree of hostility, social anxiety, depression, immoderation, vulnerability and impulsivity" (Cantador et al., 2013). In another study, individuals who possessed high levels of knowledge of art, poetry, theater, etc. demonstrated high levels of Openness i.e. "traits, such as: Intellectence, Intelligence, Culture, etc." (Ackerman, 1996). 


\section{Method}

\subsection{Participants}

Our participants are a number of 60 random male students residing in Fajr \#5 Residence Hall of Ferdowsi University of Mashhad. Students' ages vary between 18 and 23. The study is done in 2015.

\subsection{Instrumentation}

There's a questionnaire of 27 questions, namely Highly Sensitive Person Scale 2007. Other than the 27 question, some further questions would be asked about the amount of time spent on reading poetry, the amount of interest in poetry and art, and whether does the students write poetry themselves. The questionnaire items would significantly distinguish hypersensitive from other normal persons. It includes questions that evaluate high conscientiousness, awareness of subtleties, carefulness to avoid mistakes, appreciation of the arts and music, and the ability to feel acute happiness, as well as having a rich, complex inner life and social and moral sensitivity (Aron, 1999).

\subsection{Procedure}

The finalized questionnaire is comprised of thirty two questions. It has been made up of two parts. First 27 questions are a translation of an official scale, named HSPSCALE_2007. The remaining five questions are immediately added; so that the recipients think the questionnaire is one integrated whole. The five questions are the defining objects of the researcher. The questionnaires were distributed among dormitories in one day, noon and night. The selection of dormitories was done randomly. Each room received the much paper they thought they can handle based on their will and time to fill. They were supposed to fill the questionnaire till the day after. The variety of questionnaires' reception by each dormitory was between two and fourteen. The day after, the data was only partly gathered, because some rooms hadn't done the papers yet. Finally after one week, all the papers were filled and collected. The number of the distributed papers was ninety, but only sixty of them were filled. The one-week time gap of collecting the questions could have caused unpredictable factors with relation to the feeling of sensitivity, only if the questionnaires were filled over a period of time. But the stronger probability is that although some students have postponed the process of answering to later days, the mere procedure of filling the questionnaires was uninterrupted and consecutive. However, in the slightest chance that the questions were done over time, we should be attentive of unpredictable factors, and thus the results might contain fluctuations from the intended validity.

The answers to the questions were counted as 1 if they were filled 1,2, or 3 which is a low sensitivity level. On the other hand, if the answers were 5, 6, or 7, they were considered as 7 which mean a high level of sensitivity.

\subsection{Research Design}

This research is a correlational study, aiming to find the correlation between the two variables, between the interest in poetry and the degree of sensitivity. It aims to study whether an increase in the variable of degree of sensitivity results in an increase in the other variable i.e. the amount of interest in poetry, and vice versa. The research is also in some ways an exploratory research, as it is struggling to explore the situation of sensitive people and to develop new hypotheses concerning their situation. To some extent, the paper is conducted in order to inquire into the relationship between the two variables and provide insights about the relation. 


\section{Results and Discussion}

\subsection{Results}

3.1.1 What is the relationship between the degree of sensitivity and the amount of time spent on reading poetry?

To answer this question, Pearson Product-Moment Correlation Coefficient was used. The correlation between question No. 28 and sensitivity was calculated -0.14 which is negligible. The formula mentioned is Illustration 1:

$$
r=\frac{n\left(\sum x y\right)-\left(\sum x\right)(\Sigma y)}{\sqrt{\left[n \Sigma x^{2}-(\Sigma x)^{2}\right]\left[n \Sigma y^{2}-(\Sigma y)^{2}\right]}}
$$

Illustration 1

3.1.2 Are those interested in poetry more sensitive than those without any such interest? In other words, is there a difference between the sensitivity of those interested in poetry and those without any such interest?

To answer this question, an independent Samples T-Test was used. The results are shown in Table 1:

Table 1. Degree of being interested in poetry

\begin{tabular}{llllllll}
\hline & Item29b1and7 & $\mathrm{N}$ & Mean & Std. Deviation & $\mathrm{T}$ & df & Sig. (2-tailed) \\
\hline Sum27 & 1.00 & 20 & 113.10 & 12.494 & -.082 & 47 & .935 \\
& 7.00 & 29 & 113.44 & 15.046 & & & \\
\hline
\end{tabular}

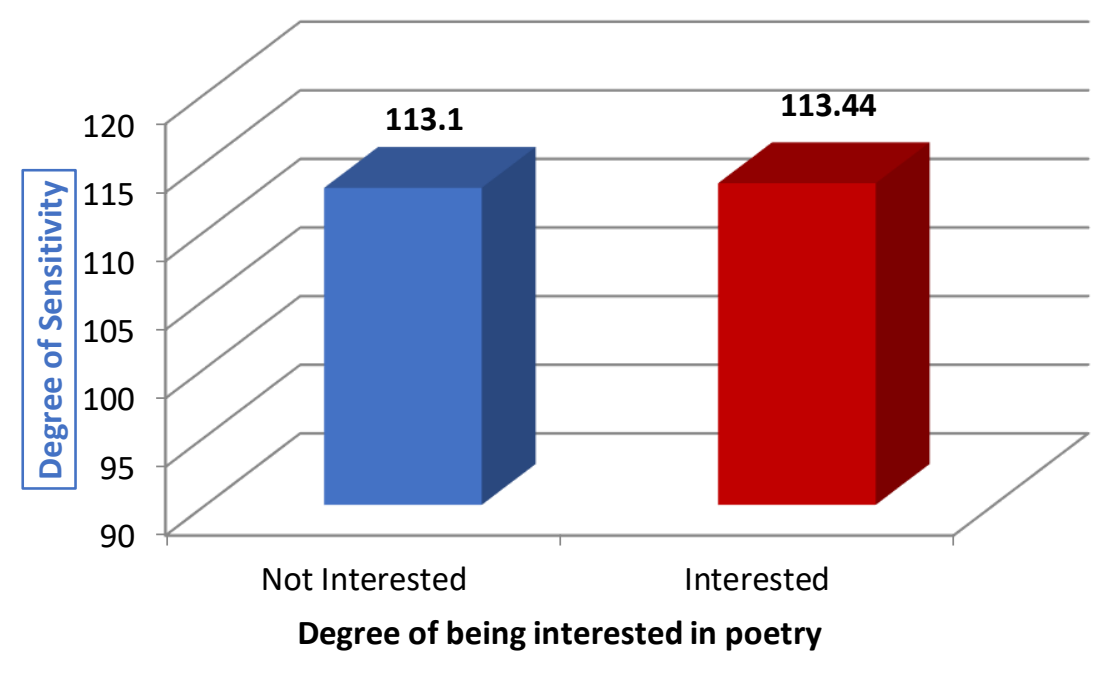

Graph. 1. Degree of being interested in poetry

3.1.3 Are those with a higher degree of creativity more sensitive than those without much creativity? In other words, is there a difference between the sensitivity of those with more creativity and those with less creativity?

To answer this question, an independent Samples T-Test was used. The results are shown in Table 2. 
Table 2. Degree of Creativity in General

\begin{tabular}{llllllll}
\hline & Item30b1and7 & N & Mean & Std. Deviation & T & df & Sig. (2-tailed) \\
\hline Sum27 & 1 & 33 & 110.37 & 15.932 & -.728 & 48 & .470 \\
& 7 & 17 & 113.89 & 16.709 & & & \\
\hline
\end{tabular}

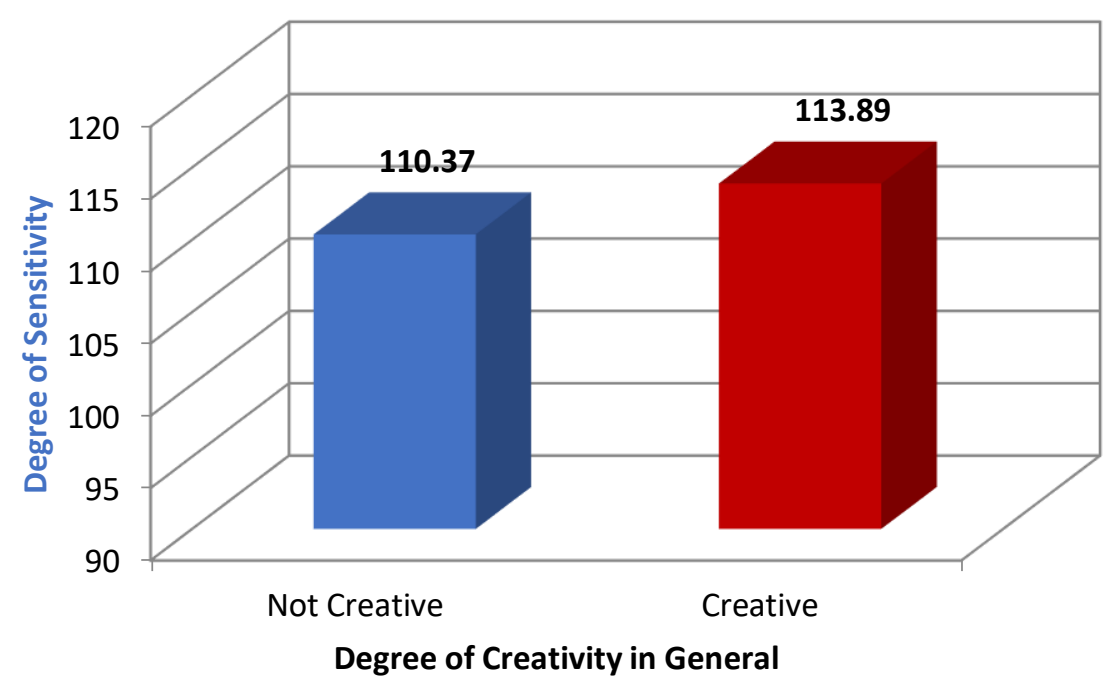

Graph. 2. Degree of Creativity in General

3.1.4 Is there any difference between the sensitivity of those who get excited while reading poetry and those who do not show such excitement??

To answer this question, an independent Samples T-Test was used. The results are shown in Table 3.

Table 3. Degree of Getting Excited While Reading Poetry

\begin{tabular}{llllllll}
\hline & Item31b1and7 & $\mathrm{N}$ & Mean & Std. Deviation & $\mathrm{T}$ & df & Sig. (2-tailed) \\
\hline Sum27 & 1 & 16 & 108.38 & 17.378 & -1.343 & 43 & .186 \\
& 7 & 29 & 115.45 & 16.666 & & & \\
\hline
\end{tabular}

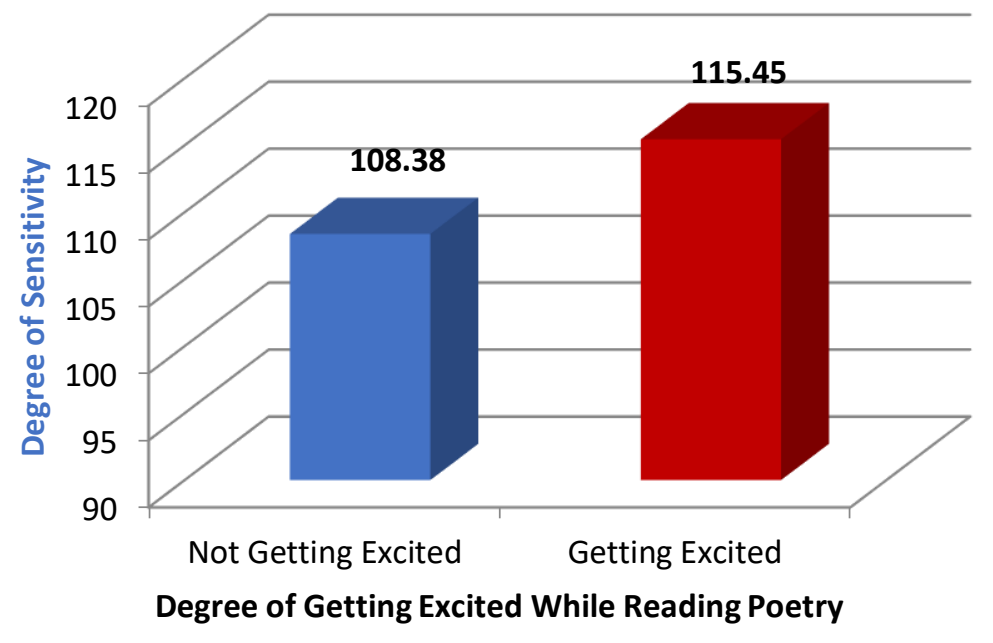

Graph. 3. Degree of Getting Excited While Reading Poetry 
3.1.5 Are those persons who understand and show some empathy for the people who are interested in poetry, more sensitive than people without any such empathy?

To answer this question, an independent Samples T-Test was used. The results are shown in Table 4.

Table 4. Degree of Empathy for Those Interested in Poetry

\begin{tabular}{|c|c|c|c|c|c|c|c|c|c|}
\hline \multicolumn{4}{|c|}{ Item $32 \mathrm{~b} 1$ and 7} & $\mathrm{~N}$ & Mean & Std. Deviation & $\mathrm{T}$ & $\mathrm{df}$ & Sig. (2-tailed) \\
\hline \multirow[t]{2}{*}{ Sum27 } & 1 & 15 & 104.55 & 19.539 & -2.256 & 49 & .029 & & \\
\hline & 7 & 36 & 116.33 & 15.850 & & & & & \\
\hline
\end{tabular}

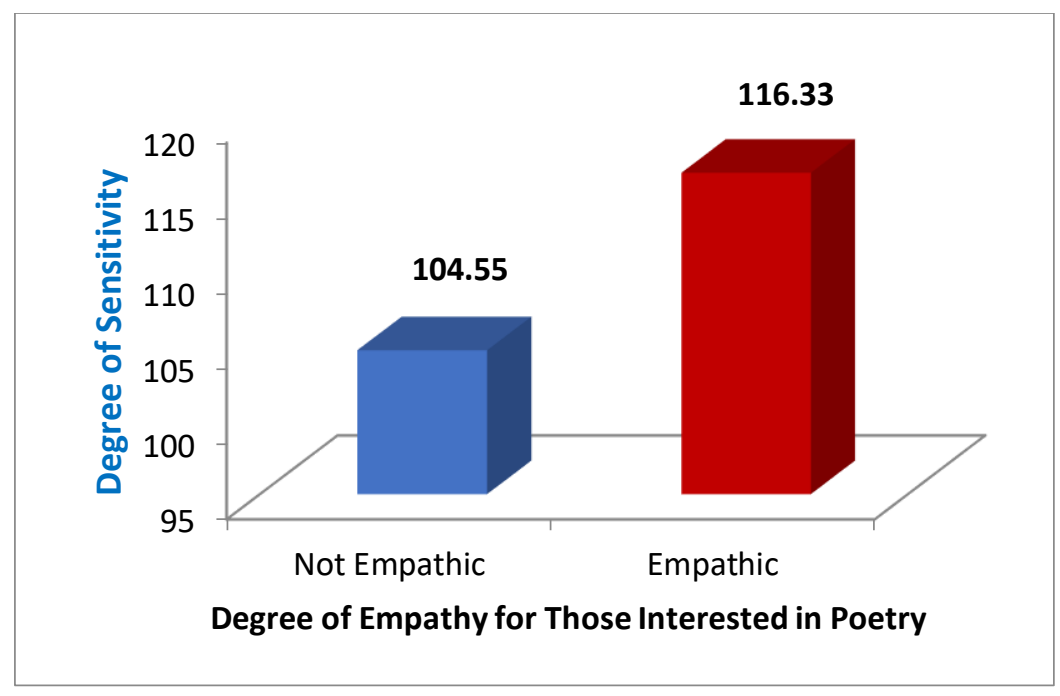

Graph. 4. Degree of Empathy for Those Interested in Poetry

\subsection{Discussion}

(1) What is the relationship between the degree of sensitivity and the amount of time spent on reading poetry? The correlation between question No. 28 and sensitivity was calculated -0.14 which implies a reverse relation, if not counted negligible. So there is no relationship founded. The reason for it can be the ordinal scale that was used for time. If the recipients were asked to write the hours or minutes of their every week reading, it would have been better.

(2) Are those interested in poetry more sensitive than those without any such interest? In other words, is there a difference between the sensitivity of those interested in poetry and those without any such interest? This is the main question of the research. But null hypothesis is not rejected. The p-value is much more than 0.5, 0.935 ; so, the null hypothesis is true and thus the hypothesis must be rejected.

(3) Are those with a higher degree of creativity more sensitive than those without much creativity? In other words, is there a difference between the sensitivity of those with more creativity and those with less creativity? Null hypothesis is not rejected. The p-value is more than $0.5,0.47$; so, the null hypothesis is true and thus the hypothesis must be rejected.

(4) Is there any difference between the sensitivity of those who get excited while reading poetry and those who do not show such excitement? Null hypothesis is not rejected. The p-value is still a little more than 0.5 , 0.186 ; so, the null hypothesis is again true and thus the hypothesis must be rejected.

(5) Are those persons who understand and show some empathy for the people who are interested in poetry, more sensitive than people without any such empathy? Only this question rejects the null hypothesis. There is a p-value of 0.029 ; so, the null hypothesis is not true.

The general results except that of question No. 5 imply that there is no significant relationship between sensitivity and the other variables. This can be a result of the small number of recipients, i.e. 60 . Moreover, the questionnaire is a translation and its reliability and validity in the translated language is under question. Another possible problem could be that the valid scale that was merged by our added five questions ending in a whole new questionnaire can result in an even lower validity of the finalized questionnaire. In addition, the possibility 
should be mentioned that the questions which were translated vaguely were mostly answered with middle choice, number 4 . Also, the translation that was provided for the choice "Moderately" was not exactly meaning something in-between "Not at all" and "Extremely"; thus, it may have caused an obstruction in the way of yielding reliable results.

The meaningful result of question No. 5 showed that the more sensitive people who are more emotionally inclined (Aron, 1999) were also more likely to feel empathy for the lovers of poetry; hence, their unconscious admiration of poetry as a consequence of their hypersensitive trait. The empathetic behavior can also explain the desperate need of hypersensitive person who are more likely to get depressed (Capron at al., 2013), to compensate for their depressive assaults through the deep attraction to lyrical contents. Thus, the result can show a favored path for those entangled in depressive moods; to reduce the mental pressures through poetry which is the unconsciously desired tool that helps "dealing with emotional problems" (Mohammadian et al., 2011).

\section{Conclusion and Suggestion}

Now that only the question No. 5 rejects its null hypothesis i.e. people who understand and show some empathy for those interested in poetry are not more sensitive than people without any such empathy, it can be concluded that people who show some empathy for the people who are interested in poetry, are more sensitive than people without any such empathy. This can suggest that those who are potential and unconscious readers and adorers of poetry, i.e. those who can empathize with their alter-egos, are of a more sensitive characteristic.

This lonely result can in a way demonstrate that the main question of the research is answered; "Are those interested in poetry more sensitive than those without any such interest?" It can be said, if people who understand and show some empathy for those who are interested in poetry were to be considered as potential lovers and unconscious seekers of poetry, it would be plausible to implicate that those with an acknowledged interest in poetry are also more sensitive than those without any interest in poetry and poetry lovers.

Maybe the reason for that is the suggestion that hypersensitive people tend to get more irritated and overwhelmed by the environment, so they seek to find solace in reading poetry. Or another interpretation could be proposed: empathic people have a high degree of sensitivity. Still, there is another possibility: those who enjoy reading poetry, for whatever reason it may be, perceive their environments with more accuracy and sensitivity. This possibility, if certified, might establish the grounds for researchers and teacher to suggest people (students) with a lower sensitivity and perception to read more poetry.

The result might seem to be developing since it is still a primary study. There are still more possibilities to be discovered by this result; so I suggest some other researchers in a more proper condition would repeat and improve these procedures and methods, in the hope that the proper results will be made. A nice suggestion for further research is that the next scholars should focus on having a sample of specifically literature-oriented people in addition to a sample of specifically people who are not interested in literature. Then they should find the correlation to the degree of sensitivity. The wide gap between these two kinds of people can bring in more elaborate results.

\section{References}

Ackerman, P. L. (1996). A theory of adult intellectual development: process, personality, interests, and knowledge. Intelligence, 227-257.

Aron, E. N. (1999). High sensitivity as one source of fearfulness and shyness: Preliminary research and clinical implications. Extreme Fear, Shyness, and Social Phobia, 1-26. doi: 10.1093/acprof:oso/9780195118872.001.0001

Brillantes-Evangelista, G. (2013). An evaluation of visual arts and poetry as therapeutic interventions with abused adolescents. The Arts in Psychotherapy, 40, 71-84. doi: 10.1016/j.aip.2012.11.005

Cantador, I., Fernández-Tobías, I., \& Bellogín, A. (2013). Relating personality types with user preferences in multiple entertainment domains.

Capron, D. W., Norr, A. M., Macatee, R. J., \& Schmidt, N. B. (2013). Distress tolerance and anxiety sensitivity cognitive concerns: Testing the incremental contributions of affect dysregulation constructs on suicidal ideation and suicide attempt. Behavior Therapy, 44, 349-358. 
Collazzoni, A., Capanna, C., Bustini, M., Stratta, P., Marzia, M., Marino A., \& Rossi, A (2014). Humiliation and interpersonal sensitivity in depression. Journal of Affective Disorders, 167, 224-227. doi: 10.1016/j.jad.2014.06.008

Eysenck, H. J. (1940). Some factors in the appreciation of poetry, and their relation to temperamental qualities. Journal of Personality, 9(2), 160-167.

Furman, R., Collins, K., Langer, C., \& Bruce, E. A. (2006). Inside a provider's perspective: Using practitioner poetry to explore the treatment of persons with mental illness. The Arts in Psychotherapy, 33, 331342. doi:10.1016/j.aip.2006.04.003

Furman, R., \& Dill, L. (2012). Poetry therapy, men and masculinities. The Arts in Psychotherapy, 39, 102106. doi:10.1016/j.aip.2012.02.001

Glasgow, M. R., Cartier, A. M., \& Wilson, G. D. (1985). Conservatism, sensation-seeking and music preferences. Person. Individ. Diff, 6(3), 395-396.

Hill, W. Y., \& Newall, J. (2004). "I don't think poetry has anything to do with accounting" and "Changes" (A teaching note and a poem). Critical Perspectives on Accounting, 15, 649-654. doi:10.1016/S10452354(03)00051-0

Kagan, J. (1994). Galen's prophecy: Temperament in human nature. New York: Basic.

Kammann, R. (1966). Verbal complexity and preferences in poetry. Journal of Verbal Learning and Verbal Behavior, 5, 536-540.

Lovecky, D.V. (1986). Can you hear the flowers singing_ Issues for gifted adults. Journal of Counseling and Development, 64, 572-575.

Mazza, N. F., \& Hayton, C. J. (2013). Poetry therapy: An investigation of a multidimensional clinical model. The Arts in Psychotherapy, 40, 53-60. doi: 10.1016/j.aip.2012.10.002

Mohammadian, Y., Shahidi, S., Mahaki, B., Zadeh Mohammadi, A., Akbarzadeh Baghban, A., \& Zayeri, F. (2011). Evaluating the use of poetry to reduce signs of depression, anxiety and stress in Iranian female students. The Arts in Psychotherapy, 38, 59-63. doi:10.1016/j.aip.2010.12.002

Peer, W. V. (1990). The measurement of metre: Its cognitive and affective functions. Poetics, 19, 259-275.

Stepakoff, S. (2009). From destruction to creation, from silence to speech: Poetry therapy principles and practices for working with suicide grief. The Arts in Psychotherapy, 36, 105-113. doi:10.1016/j.aip.2009.01.007

Vala, J. (2012). Q-methodology as the source of knowledge about the connections between the students'personal characteristics and their reader preferences. Procedia - Social and Behavioral Sciences, 69, 682-687. doi: 10.1016/j.sbspro.2012.11.461

Vala, J., \& Marešová, H. (2014). The comparison of reception of selected poems by students from varied schools. Procedia - Social and Behavioral Sciences, 112, 284 - 289. doi:

10.1016/j.sbspro.2014.01.1166 